\title{
Detection of Sleep Disordered Breathing in Patients Hospitalized with Congestive Heart Failure
}

\author{
Sunil Sharma \\ Thomas Jefferson University, sunil.sharma@jefferson.edu \\ Paul Mather \\ Thomas Jefferson University, paul.mather@jefferson.edu
}

Follow this and additional works at: https://jdc.jefferson.edu/sleepmedicinefp

Part of the Medicine and Health Sciences Commons

Let us know how access to this document benefits you

\section{Recommended Citation}

Sharma, Sunil and Mather, Paul, "Detection of Sleep Disordered Breathing in Patients Hospitalized with Congestive Heart Failure" (2015). Department of Sleep Medicine Faculty Papers. Paper 1.

https://jdc.jefferson.edu/sleepmedicinefp/1

This Article is brought to you for free and open access by the Jefferson Digital Commons. The Jefferson Digital Commons is a service of Thomas Jefferson University's Center for Teaching and Learning (CTL). The Commons is a showcase for Jefferson books and journals, peer-reviewed scholarly publications, unique historical collections from the University archives, and teaching tools. The Jefferson Digital Commons allows researchers and interested readers anywhere in the world to learn about and keep up to date with Jefferson scholarship. This article has been accepted for inclusion in Department of Sleep Medicine Faculty Papers by an authorized administrator of the Jefferson Digital Commons. For more information, please contact: JeffersonDigitalCommons@jefferson.edu. 


\title{
Detection of Sleep Disordered Breathing in Patients Hospitalized with Congestive Heart Failure
}

\author{
Sunil Sharma ${ }^{1^{*}}$ and Paul Mather ${ }^{2}$ \\ ${ }^{1}$ Department of Sleep Medicine, Thomas Jefferson University and Hospitals, Philadelphia, USA \\ ${ }^{2}$ Department of Cardiology, Thomas Jefferson University Hospital, Philadelphia, USA
}

*Corresponding author: Sunil Sharma, Department of Sleep Medicine, Thomas Jefferson University and Hospitals, Philadelphia, USA, E-mail: Sunil.Sharma@jefferson.edu

Received date: Oct 29, 2015; Accepted date: Nov 12, 2015; Published date: Nov 22, 2015

Copyright: ( 2015 Sharma S, et al. This is an open-access article distributed under the terms of the Creative Commons Attribution License, which permits unrestricted use, distribution and reproduction in any medium, provided the original author and source are credited.

\section{Editorial}

Congestive Heart Failure (CHF) is the most common cause of hospital admissions in the United States [1]. It costs over 32 billion per year in health care services, medication and missed days at work in Unites States alone [2]. An estimated 20 percent of Centers of Medicare and Medicaid Services (CMS) beneficiaries are readmitted to the hospital within 30 days of discharge. Recently The Patient Protection Affordable Care Act (ACA) of 2010 has implemented a new rule to reduce CHF readmissions, in which, from 2015 onwards, hospitals with high readmissions rates can lose $\leq 3 \%$ of their Medicare reimbursement [3].

Sleep Disordered Breathing (SDB) is a common disorder in CHF patients, with a prevalence of $50-70 \%$ [4]. Despite high prevalence the awareness of this co-morbid condition is quite low. A study on CMS patients by Javaheri et al. revealed that only $2 \%$ of the patients with $\mathrm{CHF}$ are diagnosed and treated for SDB [5].

Apart from low awareness, the fact that most CHF patients with SDB do not demonstrate classical subjective symptoms of excessive daytime sleepiness has not helped the cause [6]. Costly Polysomnography (PSG) testing may also deter referring cardiologists to take a call on nebulous grounds.

SDB, especially OSA, can significantly impact patients with CHF [7]. It has been demonstrated that that men with severe OSA have a $58 \%$ higher adjusted risk of incident heart failure than men without OSA [8]. Studies have shown that untreated OSA can worsen CHF and treatment of SDB results in improvement of ejection fraction [9]. A recent study showed that early intervention and treatment of SDB in CHF patients is associated with reduction in 30-day admissions in CHF patients [10].

The critical interventions, which may make a difference, would be 1) to consider the diagnosis of SDB in all patients admitted for CHF and 2) have a simple objective but cost effective test to risk stratify them.

Although data shows that screening questionnaires do not work in patients with CHF suspected to have SDB [11]. Our data suggests that STOPBANG questionnaire helps improving the awareness of the physician/team taking care of the patient. Our hospital Sleep Medicine program monitored the impact of screening and education of the house staff. We tracked the number of consults prompted by the positive screen to versus consults ordered directly by the admitting team. As noted in the figure, the ratio of direct consults as opposed to screen prompted consults significantly improved over time. The highresolution Plethysmography (HRPO) however, may be a game changer in implementing a cost effective strategy for effective screening of SDB in CHF patients [12].

HRPO is a significant advancement from prior generation pulseoximeters. Its ability to record signals with averaging time of 1-2 seconds and appropriate filters for artifacts makes it a highly sensitive and specific tool for screening of SDB in hospitalized patient. HRPO is also simple to use and can be applied in the hospital setting with minimal training of respiratory therapists or floor nurses. Oxygen desaturation index (usually set to capture $4 \%$ desaturation to align with CMS criteria) of $>5$, was found to be a reliable cut-off for determining risk for OSA in our study. In addition, the study also provides information on degree of desaturation and severity of apneic events, which may help with prognostication as well decision on urgency of intervention.

In conclusion, SDB has significant impact on patients with $\mathrm{CHF}$ and strategies for increased awareness, early detection, cost effective screening in hospitalized patients "captive audience" may pay rich dividends in the management of heart failure.

\section{References}

1. Pfuntner A, Wier LM, Stocks C (2013) Most frequent conditions in US hospitals 2010, Agency for Healthcare Research and Quality.

2. Heidenreich PA, Trogdon JG, Khavjou OA, Butler J, Dracup K, et al. (2011) Forecasting the future of cardiovascular disease in the United States: a policy statement from the American Heart Association,Circulation 123: 933-44.

3. Medicare Payment Advisory Commission (MedCAP) (2012) Report to the Congress: creating greater efficiency in Medicare.

4. Sin DD, Fitzgerald F, Parker JD, Newton G, Floras JS, et al. (1999) Risk factors for central and obstructive sleep apnea in 450 men and women with congestive heart failure, Am J Respir Crit Care Med 160: 1101-6.

5. Javaheri S, Caref EB, Chen E, Tong KB, Abraham WT (2011) Sleep apnea testing and outcomes in a large cohort of medicare beneficiaries with newly diagnosed heart failure, Am J Respir Crit Care Med 183: 539-46.

6. Arzt M, Young T, Finn L, Skatrud JB, Ryan CM, et al. (2006) Sleepiness and sleep in patients with both systolic heart failure and obstructive sleep apnea, Arch Intern Med 166: 1716-1722.

7. Bradley TD, Floras JS (2003) Sleep Apnea and Heart Failure Part I: Obstructive Sleep Apnea, Circulation 107: 1671-1678.

8. Gottlieb DJ, Yenokyan G, Newman AB, O'Connor GT, Punjabi NM, et al. (2010) Prospective study of obstructive sleep apnea and incident coronary heart disease and heart failure $002 \mathrm{C}$ the sleep heart health study, Circulation 122: $352-60$.

9. Kaneko Y, Floras JS, Usui K, Plante J, Tkacova R, et al. (2003) Cardiovascular effects of continuous positive airway pressure in patients with heart failure and obstructive sleep apnea, N Engl J Med; 348: 1233-41. 
Citation: Sharma S, Mather P (2015) Detection of Sleep Disordered Breathing in Patients Hospitalized with Congestive Heart Failure. J Sleep Disord Ther 4: e133. doi:10.4172/2167-0277.1000e133

Page 2 of 2

10. Kauta SR, Keenan BT, Goldberg L, Schwab RJ (2014) Diagnosis and treatment of sleep disordered breathing in hospitalized cardiac patients: a reduction in 30-day hospital readmission rates, J Clin Sleep Med 10: 1051-9.

11. Rao A, Georgiadou P, Francis DP, Johnson A, Kremastinos DT, et al. (2006) Sleep-disordered breathing in a general heart failure population: relationships to neurohumoral activation and subjective symptoms, J Sleep Res 15: 81-88.

12. Sharma S, Mather P, Efird JT, Kahn D, Cheema M, et al. (2015) Photoplethysmographic signal to screen sleep-disordered breathing in hospitalized heart failure patients: feasibility of a prospective clinical pathway, J Am Coll Cardiol HF 3: 725-31. 